\title{
2019 Canadian Geotechnical Colloquium: Mitigating a fatal flaw in modern geomechanics: understanding uncertainty, applying model calibration, and defying the hubris in numerical modelling
}

\author{
K.S. Kalenchuk
}

\begin{abstract}
This paper has been written to achieve two objectives. The first objective is to provide a discussion of the practical limitations of numerical modelling in the field of geomechanical engineering. Too many discussions of numerical methods in geomechanical engineering are centred on the impressive ability of numerical tools to conduct complex and sophisticated analyses with relative ease and efficiency. Practitioners need to have grounded conversations on numerical modelling regarding the reality that geomechanical designs are often data-limited with high degrees of uncertainty. When data limits and uncertainty are overlooked, geomechanical engineers are at risk of introducing unforeseen fatal flaws into engineering design. The second objective is to provide "how to" guidelines for model calibration using a variety of data types to qualify and quantify ground reaction. Model calibration is truly the only means to reduce numerical uncertainties. Formal training in numerical modelling is often focused on software utilization and computational methods; however, there are few opportunities for formal training on how to calibrate a model for practical engineering applications. This paper provides guidelines for calibration methods and procedures.
\end{abstract}

Key words: numerical modelling, calibration, Canadian Geotechnical Colloquium, rock mechanics, mechanistic modelling, susceptibility modelling.

Résumé : Cet article a été rédigé pour atteindre deux objectifs. Premièrement, il s'agit de fournir une discussion sur les limites pratiques de la modélisation numérique dans le domaine de l'ingénierie géomécanique. Trop souvent, les discussions sur les méthodes numériques en ingénierie géomécanique sont centrées sur la capacité impressionnante des outils numériques à mener des analyses complexes et sophistiquées avec une facilité et une efficacité relatives. Les professionnels ont besoin d'avoir des conversations fondées sur la modélisation numérique en tenant compte du fait que les conceptions géomécaniques sont souvent limitées par les données et comportent des degrés élevés d'incertitude. En négligeant les limites des données et l'incertitude, les ingénieurs géomécaniciens risquent d'introduire des défauts fatals imprévus dans la conception technique. Le deuxième objectif est de fournir des " lignes directrices » pour la calibration des modèles en utilisant une variété de types de données pour qualifier et quantifier la réaction du sol. La calibration des modèles est véritablement le seul moyen de réduire les incertitudes numériques. Les programmes de formation en modélisation numérique sont souvent axés sur l'utilisation des logiciels et les méthodes de calcul, mais il existe peu d'opportunités de formation formelle sur la façon de calibrer un modèle pour des applications d'ingénierie pratiques. Ce document fournit des lignes directrices pour les méthodes et procédures de calibration. [Traduit par la Rédaction]

Mots-clés : modélisation numérique, étalonnage, Colloque canadien de géotechnique, mécanique des roches, modélisation mécaniste, modélisation de la susceptibilité.

\section{Introduction}

The application of numerical models in geomechanical engineering can be broadly grouped into two categories based on the ultimate objective of the modelling exercise. One objective is to improve the understanding of fundamental mechanics. This objective is fairly academic by nature, but has obvious inherent benefits to practicing engineers. The other objective is to investigate the susceptibility of a geomechanical system to a particular ground reaction (i.e., rock mass response to the construction of an underground void or slope excavation). This objective is more typical for practical/industrial applications rather than academic endeavours and is generally in support of the identification and management of geomechanical risk. Susceptibility modelling will, in some cases, rely on a priori assumption of the failure mechanism. "Mechanistic modelling" is a term used in this paper to describe numerical modelling exercises focused on the first objective and the term "Susceptibility modelling" is used to describe numerical modelling exercises focused on the latter objective. When initiating a modelling exercise, the practitioner must decide the following: "Is the objective to identify susceptibility to a particular ground reaction or to replicate the fundamental mechanism?".

Susceptibility modelling and mechanistic modelling fulfill different roles in the field of geomechanical engineering. Susceptibility modelling is more common in industry applications where the representation of constitutive behaviour can be simplified or in some cases must be simplified due to budget (either time or cost) and (or) data limitations. Mechanistic modelling, on the other

Received 15 September 2020. Accepted 19 May 2021.

K.S. Kalenchuk. RockEng Inc., Suite 310920 Princess Street, Kingston, ON K7L 1H1, Canada.

Email for correspondence: kathy.kalenchuk@rockeng.ca.

(c) 2021 The Author(s). Permission for reuse (free in most cases) can be obtained from copyright.com. 
hand, investigates the fundamentals of constitutive behaviour and drives the advance of science. Mechanistic modelling generally cannot tolerate constitutive simplifications and demands more detailed data for parameterization.

This paper largely focuses on the application of numerical methods for susceptibility modelling. Discussions and examples draw from the field of rock mechanics, however the themes discussed are applicable to the broader geotechnical community. Susceptibility modelling has an important role in geomechanical risk management, particularly where there is a history of adverse conditions; when adverse ground reaction has been experienced in the past the knowledge and experience gained must be used to avoid or mitigate the hazards associated with similar ground reaction in the future. Therefore, identifying similar loading conditions in similar geotechnical domains is critical to making strategic and tactical decisions to mitigate exposure to the same or similar adverse conditions in the future. In the experience of the author, it is the practical/industrial application of numerical modelling, as a rock engineering tool, which is more commonly plagued by the shortfalls, oversights, and misplaced confidence of practitioners.

\section{State of practice}

In geomechanical engineering, design tools often utilize numerical, analytical and (or) empirical methods; for all of these, the need to manage uncertainty is equally important. Numerical tools provide practitioners improved ability (over analytical and empirical tools) to analyse complex geometric configurations (e.g., complicated excavation shapes, multiple material domains or rock mass interaction with ground support elements) and staged evaluations (e.g., construction phases or mining operational life). Computational methods have evolved rapidly and substantially alongside advances in technology and computing; we are in a state of practice where numerical modelling has become one of the most widely used design tools for practical applications. However, in parallel to significant advances in computational power and efficiencies, there are two significant shortfalls that limit many users' abilities to successfully utilize the more complex numerical methods available in our ever-advancing software and computational tools.

First, numerical methods have become increasingly easy to use (ease of use is facilitated by ever advancing commercially available software packages), and complex constitutive models can be applied with numerous parameters that cannot be directly quantified by standard data collection. Geomechanical engineers are proficient at investigating and defining the constitutive behaviour of intact materials and fracture surfaces (at the laboratory scale). However, upscaling these intact characteristics to define the fundamental constitutive behaviour of rock masses remains inherently difficult, particularly in the absence of extensive instrumentation programs. Further, the data-limited nature of geomechanical engineering often results in high degrees of uncertainty in material characterization, and so we remain reliant on empirical relationships. When the definition of appropriate parameters requires empirical curve fitting, it can be difficult for practitioners to intuitively understand the effect of each parameter on the model. Some parameters also inadvertently incorporate counteracting effects, which results in non-unique solutions for model parameterization (Rahjoo et al. 2018).

Data limitations, compounded by limitations in the empirical parameterization of rock mass constitutive behaviour, can result in significant uncertainty. This uncertainty is too commonly lost (or forgotten) somewhere between numerical data input and result output. Perhaps this is due to practitioners placing too much reliance on numerical "black boxes" to generate computations with little or no requirement for users to truly understand the underlying formulations. Or perhaps it is the sophisticated, high-resolution graphics that project numerical results which enable users (perhaps subconsciously) to negate the transfer of uncertainty from model input to model and design output. Ignoring design uncertainty can result in failure to recognize fatal flaws pertaining to safety and economics.

The second shortfall is related to a generational gap in training. Twenty years ago, basic coding skills were the typical extent of training in computational methods in undergraduate geological or geotechnical engineering programs. Graduates from before that time would have been exposed to even less, if any, formal university training in computational methods. Young people going through university today have much wider exposure to numerical modelling as a design tool. However, it is often the more seasoned generations that have enough practical experience to identify erroneous numerical output when they see it, while the more recent graduates may lack experience to easily identify numerical errors in design outputs. Of course, these comments are wide generalization; there are many young people excelling in the field of geomechanics with excellent early career experience and critical thinking skills, and there are also many well-experienced practitioners who competently know their way around computation tools.

\section{Numerical representation of rock masses}

The process of numerical model calibration must account for the problem scale (local vs. global) and representative boundary conditions, material domains (based on geological and (or) geotechnical domains), constitutive model, and material properties. Before any modelling study is initiated, practitioners must consider:

- What type of model is appropriate?

- What constitutive model is appropriate and what is known about the material properties?

- What boundary conditions are required and how should the boundary conditions be implemented?

- How much uncertainty is there in the above listed considerations?

The following sections provide discussion of these considerations.

\section{What is the right type of model?}

The selection of a modelling technique (finite element, finite difference, discrete element, boundary element, particle code, finite-discrete element method (FEMDEM) or hybrids) should fundamentally be decided based on the problem being investigated with consideration for the anticipated failure mode (as dictated by rock mass characteristics and boundary conditions). Figure 1 illustrates the appropriateness of continuum vs. discontinuum vs. hybrid numerical methods for different ground reactions based on fracture intensity and loading conditions. The concepts in this figure provide reasonable guidelines for selecting a modelling method, however this figure does not address modelling objective or scale. The selection of a modelling tool is also influenced by the modelling objective (Susceptibility vs. Mechanistic), and the scale of the problem being investigated. For example, if a modelling study aims to investigate the behaviour of an excavation (local scale) in jointed rock mass in high-stress conditions for detailed stability assessment and deformation-based ground support design, a discontinuum or hybrid model would be most appropriate to capture the mechanics. However, if the objective is to investigate the susceptibility of mine infrastructure (global scale) in jointed rock under high stress conditions to the risks associated with stress induced damage, a continuum model would be more appropriate due to the inherent challenges with volumetric up-scaling of discontinuum and FEMDEM codes as discussed below.

Continuum based modelling will not reproduce the correct fundamental mechanism most of the time, particularly under low confinement conditions. As an example, it is very difficult to 
Fig. 1. Selection of modelling method based on failure mode.

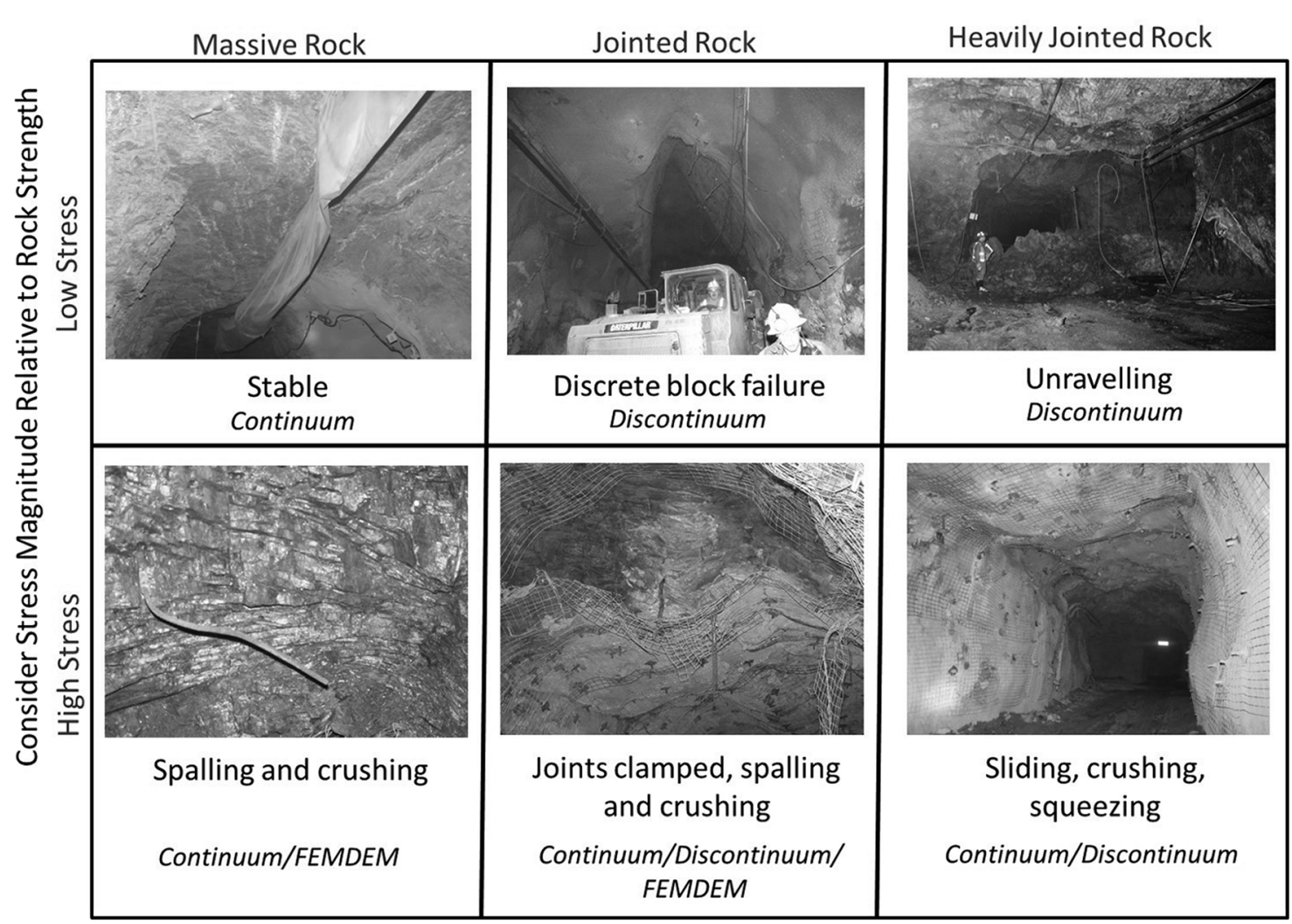

replicate spalling behaviour in a continuum model. Continuum models conventionally utilize shear-based failure criteria, and extensile failure is a key component of spalling at the microscale (Diederichs 2003). For this reason, the typical shear-based failure criteria which are intrinsically programmed into most commercially available geotechnical modelling software can make it difficult to accurately predict spalling depth and associated material bulking (which is important for deformation-based support design, Eberhardt 2019). Of course, under high confinement, shear failure models are typically appropriate. It is noted that some techniques do exist for continuum representation of rock masses under low confinement; e.g., the S-shaped or trilinear failure envelope provided by Diederichs (2003); and constitutive models continue to advance, e.g., the three-dimensional extensional shear failure criterion provided by Rahjoo and Eberhardt (2019).

Discrete element numerical methods can reasonably reproduce mechanisms where failure and deformation are dominated by the behaviour of contacts and fracture networks. Where intrablock deformability and (or) plasticity must be captured, hybrid codes can be utilized. However, computational efficiencies are penalized, in some cases prohibitively so, making upscaling difficult. FEMDEM and particle codes arguably provide superior ability to capture fundamental mechanisms (particularly exceeding the continuum limitations at low confinement); however, FEMDEM and particle code simulations are also very difficult to scale-up, largely due to inherent limitations in run-time efficiencies. Further, with FEMDEM and particle-based codes it can be very difficult to parameterize the input parameters controlling contact behaviour.

\section{What is the right constitutive model?}

Rock mass behaviour is controlled by the mechanical characteristics of intact rock and fracture networks. The mechanical behaviour of natural fractures can be smeared into a continuum, represented by ubiquitous joint or anisotropic strength models, or explicitly simulated. Smeared continuums define representative constitutive behaviour empirically based on intact rock and jointing conditions (e.g., Generalized Hoek-Brown criterion; Hoek et al. 2002). Ubiquitous joints and discrete representation of structures require that intact materials and fractures, or fracture networks, be parameterized and assigned constitutive models individually.

The complexity of constitutive behaviour applied to a numerical simulation can vary drastically. Linear-elastic models are simplistic, relying only on material stiffness and the bounding stress conditions as inputs. Their execution and interpretation are straightforward and, despite the obvious limitations in producing the fundamentally correct mechanisms, they provide sufficiently reasonable output for many applications of susceptibility modelling. Non-linear modelling of materials with complex behaviour (including yielding and failure processes) requires the definition of peak and post-peak constitutive parameters. Due to the inherent limitations in geotechnical data collection and fundamental difficulties in the post-peak parameterisation of a rock mass, the numerical simulation of plasticity can exponentially increase computational uncertainties. However, as discussed in Rahjoo et al. (2018) realistic pre- and post-peak confinement dependent and history dependent material behaviour are absolutely required for mechanistic modelling studies, and of course (where supported by sufficient data) can add value to susceptibility modelling.

The representation of complex constitutive behaviours in susceptibility modelling must be justified by the availability of sufficient material testing and instrumentation data to quantify the parameters controlling complex non-linear behaviour. This databased justification of increased complexity is required because 
Fig. 2. Complex in situ stress gradients associated with the distribution of geological units and structures (back analysed from borehole break out, Leriche et al. 2017). HQ and NQ diamond drill bit sizes; MTBS, metabasalt; MTGB/MXGB, metagabbro; MTSD, metasediments; QDIA, quartz diabase; Rhy, rhyolite; $\sigma_{\mathrm{H}}$, maximum horizontal stress; $\sigma_{\mathrm{h}}$, minimum horizontal stress; $\sigma_{\mathrm{v}}$, vertical stress.

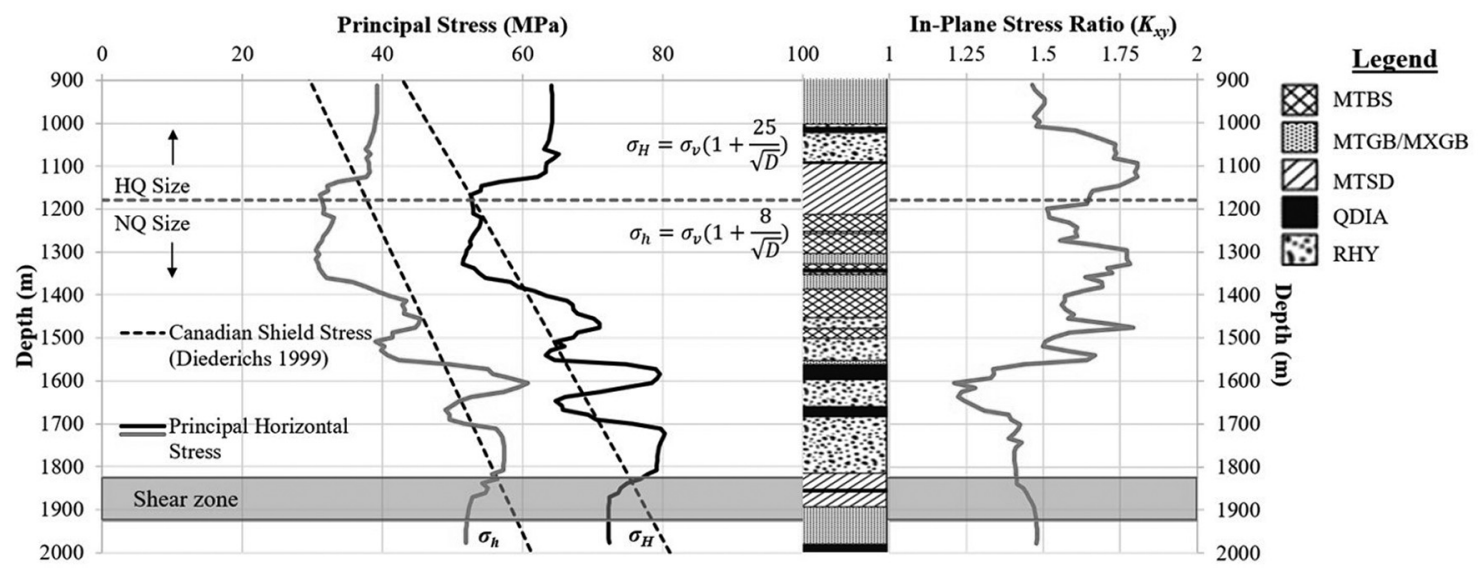

numerical solutions to geomechanical analyses are often nonunique. In many cases, multiple combinations of input parameters and boundary conditions can result in very similar output, as a demonstrated by Kalenchuk et al. (2017). However, the stressstrain paths leading to an ultimately similar end result may be substantially different and influence the fundamental interpretation of the underlying mechanisms. Further, when it is impossible to discern which combination of input values and boundary conditions are "correct" for a back analysis of observations, the confidence in forward predictions can be severely limited.

Despite the exponential increase in uncertainty from linear to non-linear modelling, the trend in the state-of-practice in numerical simulations has been towards increasingly complex models. This trend towards increasing complex models is facilitated by the continuous progress towards easy to use commercially available software packages. Unfortunately, the improved ease of use inherently facilitates the misuse of complex constitutive behaviour and failure to understand, or acknowledge, the inherent uncertainties in model results. It is often argued that reducing the number of parameters in a numerical model unfavorably affects the precision of results, and there is an air of arrogance amongst numerical modelling practitioners (experts and novices alike) that more sophisticated parameterization is somehow indicative of superior knowledge or ability. However, a truer limitation to the accuracy of modelling results is the incorrect parametrization of a numerical model. The correctness of parameterization is a function of data availability, and in data-limited studies the odds of applying incorrect parameters increase rapidly with added constitutive complexity. Increased parametric complexity may produce a more precise result, however it is very easy to precisely get the wrong answer. Perceived accuracy can lead to flawed confidence.

\section{What are the right boundary conditions?}

Boundary conditions define the loading conditions applied to a mechanical study. In geomechanics, the loading conditions most typically considered are stress state and water; thermal influences are also worth noting in some applications. This discussion will focus on how the stress state is quantified and applied, as hydro- and thermo-mechanically coupled processes are outside of the calibration processes discussed later in this paper.

The far-field or virgin stress state in rock is impacted by numerous factors. Negating the impact of water and heat, these factors can include: the weight of overlying strata, plate tectonics and the geological history of a site (glacial loading, erosional events, etc.). Knowledge of the magnitude, gradients and direction of the in situ virgin stress state is an essential component of numerical modelling, and these components of boundary conditions can be even more difficult to define than constitutive behaviour and material parameters. Often, an approximation regarding stress state is applied (the accuracy of this approximation is influenced by the available data - in situ stress testing, seismic or geophysics, borehole breakout, world stress map, etc.). Model calibration is then required to narrow in on the true in situ stress conditions.

In nearly all geological settings stress gradients occur between lithological units with contrasting stiffness. Variance in elastic moduli between lithological or geotechnical domains will result in in situ virgin stress gradients (Leriche et al. 2017 provide an example of complex in situ stress conditions back-analysed from borehole breakout, Fig. 2). This is due to the natural strain history of a rock mass. Nearly all geological settings have incurred some strain history; this may be due to complex tectonic history or simply due to gravitational loading in a depositional setting.

Virgin in situ stress states are rarely homogeneous. Yet, the most common means to initiating stress in a numerical model is to simply initialize a global stress state (typically either homogeneous or with gradients associated with depth - depending on the scale of the simulation). The "correctness" of the stress boundaries applied to a numerical model is influenced not only by having the correct regional trends (magnitude and direction), but also by the methods used to initialize the stress state. Is it sufficient to simply initialize in situ stresses using a homogenous or depth-dependent gradient function? For most cases in rock engineering - particularly for complex geological settings the simple answer is no, most definitely not.

Strain-based stress initialization is required to capture virgin stress state gradients associated with natural stiffness contrasts in a numerical model. Figure 3 illustrates an example of initialized stress states based on strain-based stress initialization. Despite the conceptual "correctness" of strain-based stress initialization to capture stiffness-driven stress gradients, effective implementation of this approach requires extensive calibration to observational data and (or) in situ stress testing. It is also important to recognize that strain-based stress initialization relies heavily on a reliable geological model to define the approximate boundaries between lithological units or a solid-model representing three-dimensional geotechnical domains; in the absence of at least one or the other it is nearly impossible to estimate how the in situ stresses may vary spatially.

\section{Calibration techniques}

Model calibration is the process of correlating observations of actual ground behaviour to numerical output, thereby refining the site-specific strength criterion and boundary conditions. The 
Fig. 3. Virgin stress state applied to numerical model using strain-based stress initialization: (a) geological domains; $(b)$ contoured major $\left(\sigma_{1}\right)$ and minor $\left(\sigma_{3}\right)$ principal stresses.

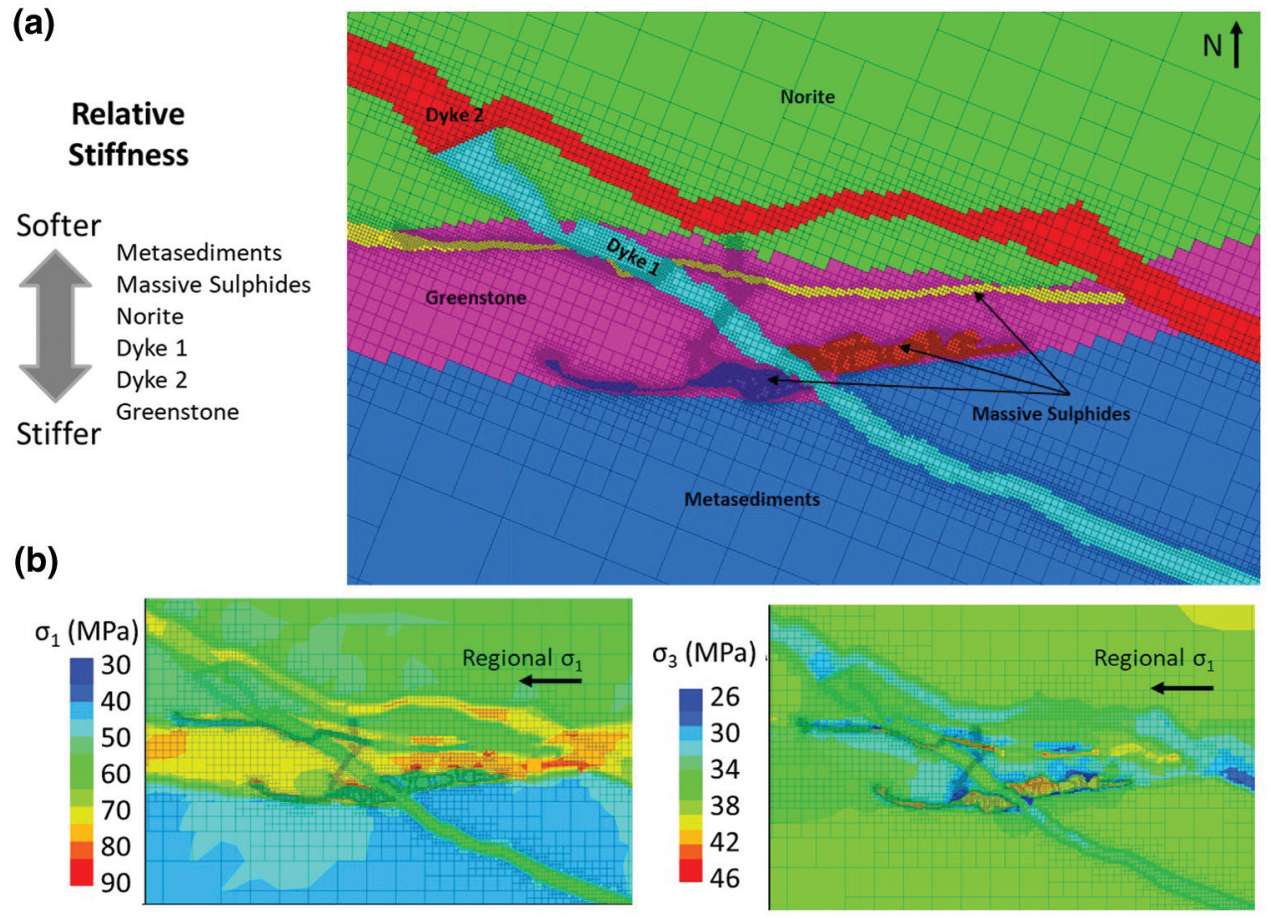

back analysis of observed and measured ground reaction is fundamental to achieving confidence in numerical output. Any numerical simulation should have some degree of model calibration, with the exception of green-field studies (which must instead rely on thorough sensitivity testing).

Best-practices in numerical simulations for geomechanical engineering applications demand model calibration, however there are few formal training opportunities to learn calibration methods. The following sections describe a framework to guide geomechanics professionals through model calibration (which is summarized in Fig. 4) and discuss model calibration procedures for different types of ground response data. The sub-sections highlight the opportunities and limitations of specific types of ground reaction data. The main focus of these discussions is on calibrating global models (e.g., mine scale). The calibration of local models (excavation scale) relies on the same general principles and procedures, however with local models it is generally easier to statistically quantify goodness of fit. In the experience of the author, there is great value in establishing a calibrated global model (typically susceptibility modelling) prior to a detailed local model (more often mechanistic modelling) to reduce uncertainties in boundary conditions prior to exploring complex constitutive laws and the associated parameterization.

\section{Qualitative vs. quantitative calibration}

Depending on the type and quantity of ground reaction data, model calibration efforts can range from qualitative to quantitative (Crockford et al. 2015). Qualitatively calibrated models provide indications of different classes of behaviour under varied loading conditions, while quantitatively calibrated models provide direct indications of likely rock mass stress-strain behaviour. Both approaches facilitate risk management (pertaining to safety and economics), however quantitatively calibrated models typically have reduced uncertainty, meaning designs may be optimized through use of lower factors of safety.
Quantitative calibration is exceptionally more difficult to achieve and requires high-quality instrumentation data, as has been demonstrated by various authors (e.g., Kalenchuk et al. 2017; Crockford et al. 2015; Crowder et al. 2006). Truly quantitative calibration requires instrumentation to be installed sufficiently early relative to the ground reaction process so that the complete stress-deformation path is captured without significant gaps. For global-scale calibration, physical measurements provided by instrumentation must be taken at numerous locations to differentiate global rock mass response from localized influences on ground reaction. For these reasons, qualitative or semiquantitative calibration is often the best that can be achieved in global-scale modelling applications.

\section{Ground behaviour models and categorized ground response indicators}

The first and most important phase of any model calibration is the development of a "ground behaviour model", a term described by Palleske et al. (2017) as the compilation of all available site geotechnical data into a single (three-dimensional) platform. A ground behaviour model includes (but is not limited to):

- Raw geotechnical data (mapping, core logs, laboratory results)

- Domained rock mass conditions

- Geology (lithology, structure, alteration, etc.)

- As-built excavation and design geometries

- Instrumentation data

- Records of ground support performance

- Damage and mechanism mapping

- Records of falls of ground or failures

- Rehabilitation records

- Water

The second step in susceptibility model calibration is the categorizing of ground response. Ground response categorization describes the significance of ground reaction, with consideration for hazard and risk. This process is often site-specific and is closely 
Fig. 4. Framework for model calibration.

\begin{tabular}{|c|c|c|c|c|}
\hline \multicolumn{5}{|c|}{ 1. Development of a Ground Behavior Model } \\
\hline Geometry and Boundary Conditions & & eotechnical Parameters & & und Reaction Indicators \\
\hline $\begin{array}{l}\text {-Geology } \\
\text {-As-build excavation and design } \\
\text { geometries } \\
\text {-Water } \\
\text { - Geotechnical domain boundaries } \\
\text { - In situ stress } \\
\end{array}$ & $\begin{array}{l}\cdot \text { Raw } \\
\cdot \text { Roc } \\
\cdot \text { - Inta } \\
\cdot \text { Con }\end{array}$ & $\begin{array}{l}\text { geotechnical data } \\
\text { mass classification } \\
\text { t rock properties } \\
\text { titutive models }\end{array}$ & $\begin{array}{l}\text {-Instru } \\
\text {-Micro } \\
\text {-Dama } \\
\text {-Falls } \\
\text { - Grour }\end{array}$ & $\begin{array}{l}\text { nentation data } \\
\text { seismicity } \\
\text { se and mechanism Mapping } \\
\text { f ground } \\
\text { d support performance }\end{array}$ \\
\hline \multicolumn{5}{|c|}{ 2. Ground Reaction Categorization } \\
\hline \multirow{3}{*}{$\begin{array}{l}\text { When } \\
\text { Where } \\
\text { Magnitude/Intensity/Frequency } \\
\text { Mechanism }\end{array}$} & \multirow{3}{*}{\multicolumn{4}{|c|}{$\begin{array}{c}\text { Damage mapping: damage intensity, mode of failure [tension/spalling/squeezing], } \\
\text { orientation, changes with time }\end{array}$}} \\
\hline & & & & \\
\hline & & & & \\
\hline \multicolumn{5}{|c|}{$\begin{array}{c}\text { Considerations: } \\
\begin{array}{c}\text { Does ground reaction vary between geotechnical domains (categorization may be domain specific)? } \\
\text { Does ground reaction mechanism change over time? }\end{array}\end{array}$} \\
\hline \multicolumn{5}{|c|}{ 3. Numerical Back Analysis } \\
\hline \multicolumn{5}{|c|}{$\begin{array}{l}\text { The systematic variation of model input until numerical simulated response matches observed response. } \\
\text { Note: All model input is subject to calibration (each boundary condition and each geotechnical parameter). } \\
\text { Caution: Solutions may be non-unique. }\end{array}$} \\
\hline Type of Calibration & Qualitative & \multicolumn{2}{|c|}{ Semi-Quantitative } & Quantitative \\
\hline Model Complexity & Low to High & \multicolumn{2}{|c|}{ Moderate to High } & High \\
\hline \multirow{2}{*}{$\begin{array}{c}\text { Examples of Data } \\
\text { Types }\end{array}$} & $\begin{array}{l}\text { isual } \\
\text { rvations }\end{array}$ & \multicolumn{2}{|c|}{$\begin{array}{c}\text { - Seismicity } \\
\text { - Deformations (no measured stress) }\end{array}$} & $\begin{array}{l}\text { Measured displacements } \\
\text { and stress change over } \\
\text { time }\end{array}$ \\
\hline & & \multicolumn{2}{|c|}{$\begin{array}{l}\text { In parallel to qualitative } \\
\text { calibration }\end{array}$} & $\begin{array}{l}\text { In parallel to qualitative and } \\
\text { semi-qualitative calibration }\end{array}$ \\
\hline
\end{tabular}

tied to the available means of risk mitigation (Figs. 5 and 6 provide examples). The concept here is that a particular ground reaction, in a particular geotechnical domain (consistent rock mass conditions), can be attributed to a specific stress-strain path (within some tolerance). Therefore, when a calibrated model is used for forward simulations, practitioners can resolve that a reasonably similar stress-strain path is likely to contribute to the same category of ground reaction (with known implications to engineering design and project operations).

The process of developing a ground behaviour model and categorizing ground response to signify the associated hazard level is arguably the most important step in any susceptibility model calibration exercise. The exercise of data analysis, spatial interpretation, and identification of hazard implications ensures that the practitioner, or team of practitioners, tasked with numerical simulation is more likely to understand, or at least conceptualize, the fundamental mechanics of the problem prior to developing a simulation. This not only helps to streamline the calibration process, but also facilitates pragmatic results interpretation and meaningful design outcomes.

\section{Calibrating to visual observations}

Damage and mechanism mapping provide visual observations which can form the basis for mine-scale qualitative model calibration in data-limited situations where conventional monitoring data are not available. Damage and mechanism mapping are also commonly relied on to complement physical measures of ground reaction data acquired by conventional instrumentation or microseismic data. Calibrating to physical measures is discussed in later sections of this paper. Here the focus is on calibration situations where visual observations are the only available record of ground reaction.

The key to collecting visual observations of ground reaction is ensuring that the data are collected in a non-subjective and repeatable manner. This generally requires trained professionals with some experience for field recognition of damage mechanisms. Damage and mechanism mapping provide data pertaining to the mode of damage, extensiveness of damage and the implications to excavation performance (i.e., support effectiveness and excavation serviceability). An excellent example of guidelines for non-subjective and repeatable damage mapping is provided by Sandy et al. (2010). Where a rock mass has well-developed stress induced fracturing, damage and mechanism mapping should incorporate probe holes to improve measures of the depth of damage around an excavation periphery.

Routinely implemented damage and mechanism mapping can provide data with excellent spatial and temporal coverage describing the intensity of stress induced rock mass and excavation damage. These qualitative data must be categorized to define bins of hazard severity (e.g., Figs. 5 and 6), and when compiled in a comprehensive ground behaviour model, each mapping 
Fig. 5. Categorization of seismogenic ground response (after Kalenchuk et al. 2014). $M_{N}$, Nuttli magnitude; S0-S3 denote damage intensity scale (see Fig. 6).

\begin{tabular}{|c|c|c|c|c|c|c|c|}
\hline Risk Level & LOW & MODERATE & \multicolumn{3}{|c|}{ HIGH } & SEVERE & \multirow{4}{*}{$\begin{array}{l}\text { Ground } \\
\text { Response }\end{array}$} \\
\hline $\begin{array}{l}\text { Anticipated } \\
\text { Seismicity }\end{array}$ & $M_{N}<-0.5$ & $-0.5<M_{N}<0.5$ & - & \multicolumn{2}{|c|}{$0.5<M_{N}<1.5$} & $1.5<\mathrm{M}_{\mathrm{N}}$ & \\
\hline $\begin{array}{c}\text { Anticipated } \\
\text { Damage }\end{array}$ & So-s1 & S2 & S3+ & \multicolumn{2}{|c|}{ S3+ } & S3+ & \\
\hline $\begin{array}{l}\text { Ground } \\
\text { Reaction }\end{array}$ & N/A & N/A & Squeezing & $\begin{array}{l}\text { Strain } \\
\text { Bursting }\end{array}$ & $\begin{array}{l}\text { Pillar } \\
\text { Bursting }\end{array}$ & Bursting & \\
\hline $\begin{array}{l}\text { Support } \\
\text { Standard }\end{array}$ & \multicolumn{2}{|c|}{ Standard Support } & Class C & Class B & Class A & Class A & \multirow{2}{*}{$\begin{array}{c}\text { Implication to } \\
\text { Design and } \\
\text { Operations }\end{array}$} \\
\hline $\begin{array}{l}\text { Re-entry } \\
\text { Time }\end{array}$ & \multicolumn{2}{|c|}{ At background } & \multicolumn{3}{|c|}{5 hours after background } & $\begin{array}{l}24 \text { hours after } \\
\text { the event or } 5 \\
\text { hours after } \\
\text { background }\end{array}$ & \\
\hline
\end{tabular}

Fig. 6. Categorization of ground response based on damage intensity.

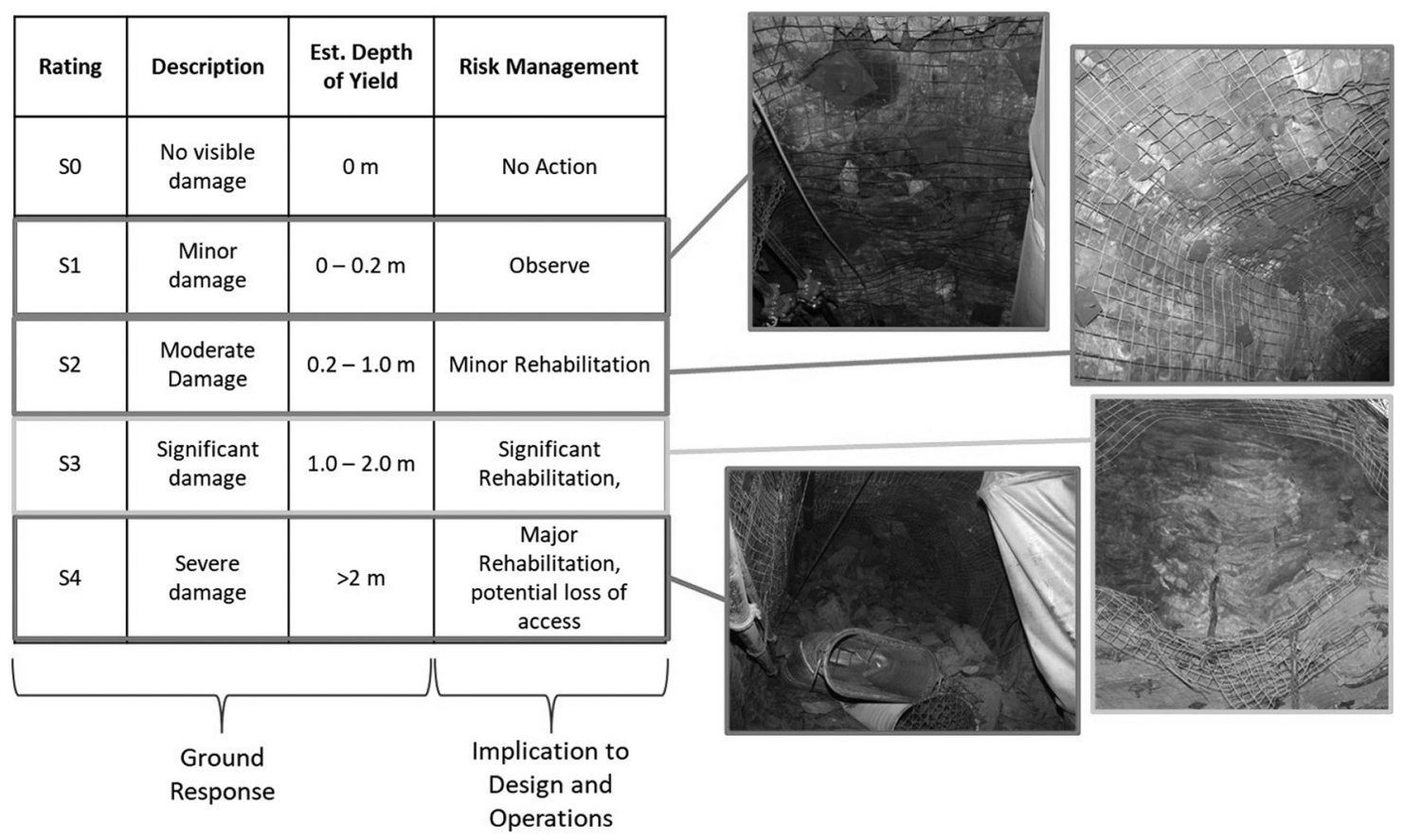

observation is also spatially correlated to geological and geomechanical domains.

It is important to recognize that visual observations provide no direct measure of constitutive behaviour. Once visible rock mass yield is evident it is impossible to know where the rock mass is on the stress-strain path (Fig. 7), this is a significant limitation to model calibration as it is very difficult to define (with certainty) the shape of that stress-strain path; post-peak parameterization is next to impossible. For this reason, constitutive models should be kept as simple as possible. Recall that the justification of constitutive model complexity must be based on the data available to characterize the rock mass stress-strain path.

Model calibration to damage and mechanism mapping is fairly straightforward. The simplest means is to sample the numerical stress state output at each damage mapping observation point. It is important that the stress state be sampled at appropriate model stages. When sampling the model state for comparison to damage observation points, practitioners must be cognisant of when, over the operational or construction history, the damage may have accumulated (the induced stress state at the time of observation may not be the same as the induced stress state at the time of damage accumulation). It is good practice to track the stress path for each excavation point as the numerical simulation runs through the historical excavation or construction sequence and identify the most adverse loading experienced.

Figure 8 provides an example of real damage mapping data utilized for model calibration. Here, the numerically predicted stress states at field observation points are plotted in Principal 
Fig. 7. Limitations to qualitative calibration.

Once visible rock mass yield is evident it is impossible to know where the rock mass is on the stress-strain path. It is also impossible to know the shape of that stress-strain path.

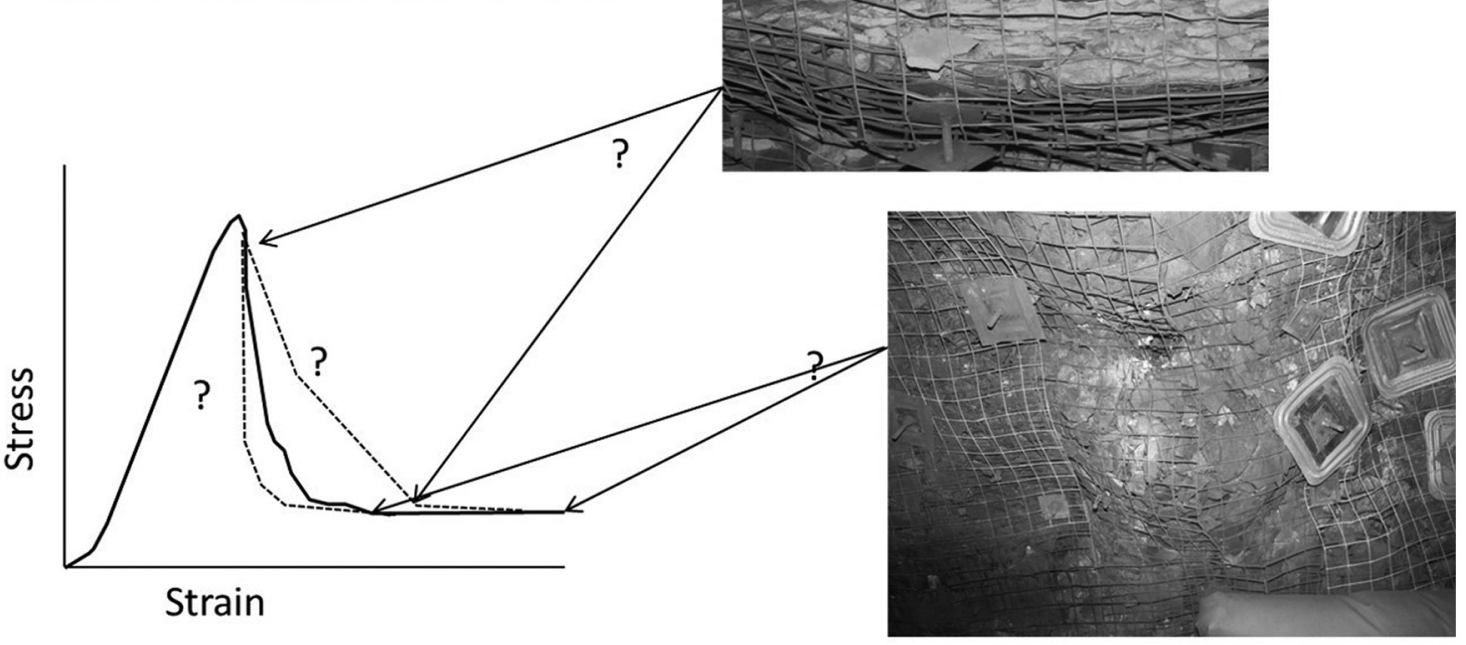

Fig. 8. Qualitative calibration to visual observations of stress-induced damage (after Kalenchuk et al. 2014).
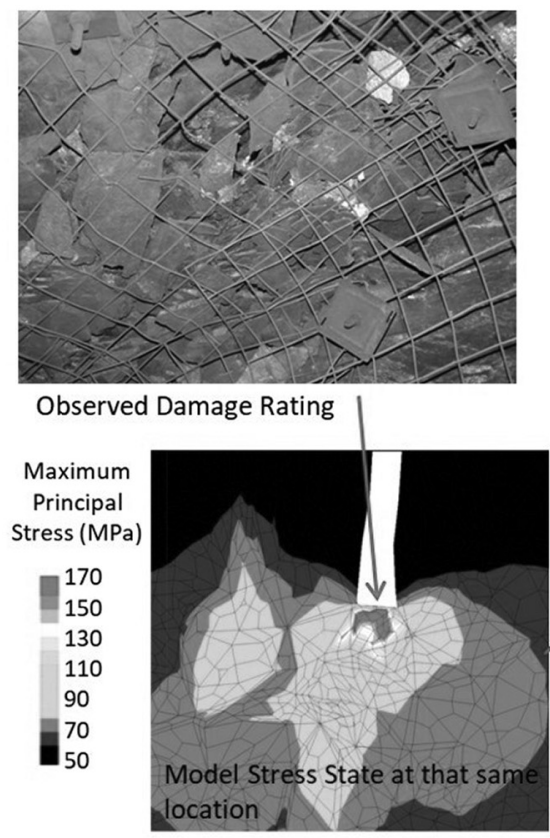

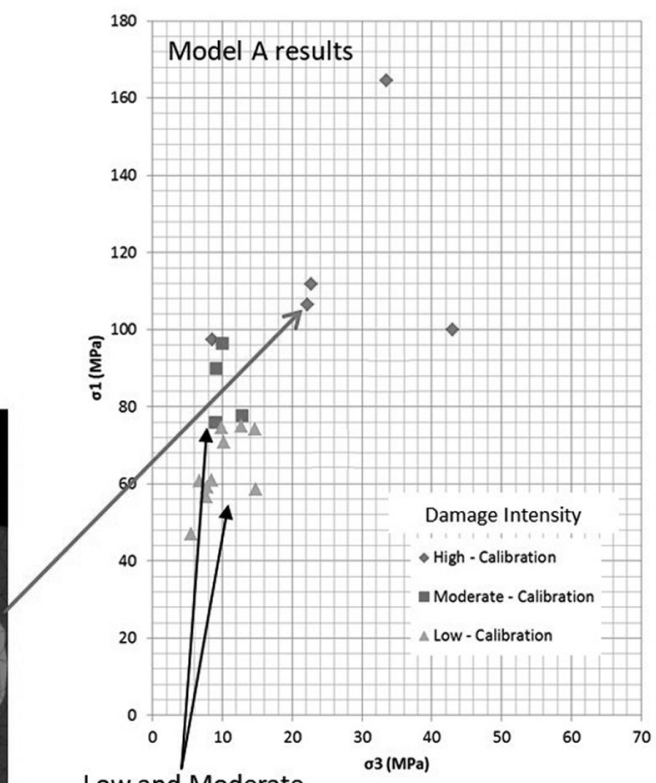

Low and Moderate categories are statistically distinguishable

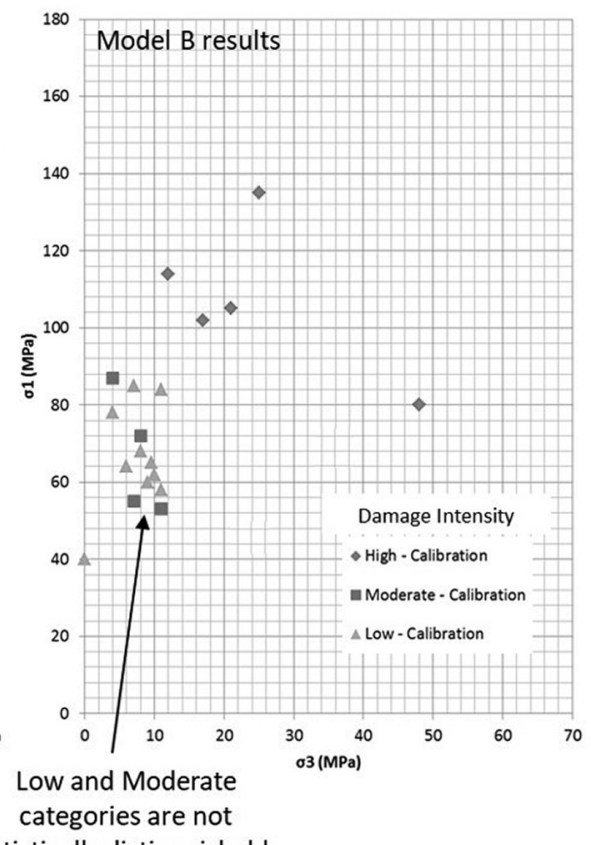
statistically distinguishable
Stress space. A well calibrated model will result in distinct populations of data related to each category of hazard intensity. This example illustrates the numerical results for two different stress tensors. Model A utilizes a hypothesised stress tensor based on observations of the spatial distribution of damage accumulation relative to excavation geometry and Model B utilizes a regional stress tensor based on in situ stress measurement data from neighbouring mining operations in the project district. The two tensors utilize similar far field stress magnitudes, however the orientations of the major and intermediate principal stresses (both being horizontal) are rotated by roughly $90^{\circ}$. Both models have distinct populations for the high damage category. Model A has distinct populations for the moderate and low categories, while for model B it is impossible to numerically distinguish the conditions of moderate and low damage intensity. Therefore, it can be concluded that model $\mathrm{A}$ has a better calibration of 
Fig. 9. Cautionary limitation to calibration with instrumentation data. The timing of instrumentation installation can have significant impacts on the interpretation of rock mass state.

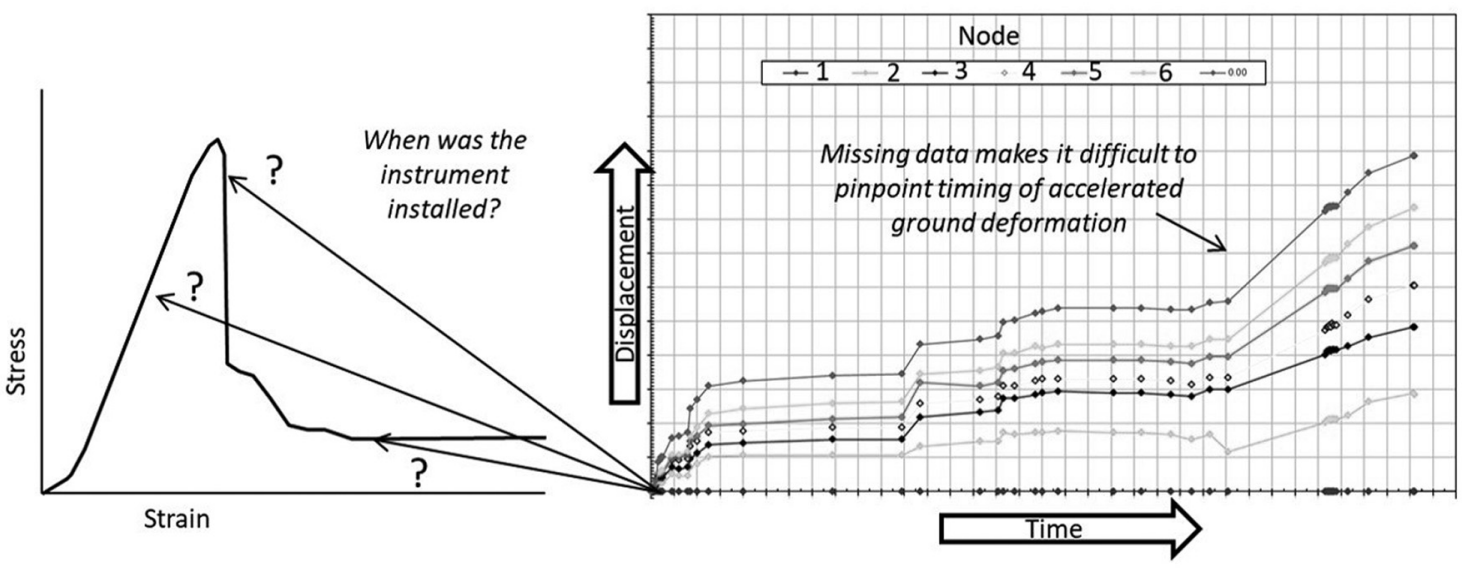

boundary conditions. Now that boundary conditions have been narrowed down, the next steps in ongoing calibration efforts would focus on refining material parameterization in Model A to improve statistical goodness of fit (i.e., to reduce scatter), thereby improving model reliability. The goodness of fit for model calibration by this technique can be defined by how well each hazard intensity bin can be statistically distinguished from other hazard intensity bins based on numerical model results. This process can then be taken one step further to statistically evaluate the probability of occurrence based on event cluster distributions (Wiles 2007 provides a comprehensive discussion).

\section{Calibrating to conventional instrumentation}

In recent decades there has been a significant increase in the use of conventional instrumentation for geomechanical applications. Instrumentation can provide physical measures of rock mass stress state and strain accumulation. Stress, and stress changes, can be sampled using various types of stress cells and geophysical methods, and strain is measured by displacement monitoring. Surficial deformation monitoring can be achieved by tools such as lidar, radar and closure meters; down hole measures can be obtained by tools such as extensometers or inclinometers.

One significant challenge when applying conventional instrumentations to model calibration is spatial resolution (particularly at a global scale), it is nearly impossible to measure a fully three-dimensional picture of stress and strain (unless one has the privilege of a limitless budget!). Individual instruments provide measurements at specific points in space and practitioners must be cognisant of whether observations reflect a global ground response or a localized mechanism.

A second challenge is that a combination of ground deformation and stress measuring instruments are required to capture the complete stress-strain path for a failing rock mass; a necessity for truly quantitative calibration. In many practical applications, displacement monitoring is quite common, however stress monitoring is not as often available.

A third challenge is temporal coverage. Instrumentation is commonly installed after some amount of rock mass damage has accumulated; this is particularly true in mining applications where instrumentation is too often used reactively in situations with ground reaction challenges. Also, gaps in the recording history introduce further uncertainty as to what the full shape of the stress-strain path looks like. Technological advances have helped to manage temporal limitations to some extent; automated data acquisition has substantially improved temporal tracking. Figure 9 provides an illustrates of measured displacements along a borehole extensometer installed perpendicular to the surface of an underground excavation. The data shown in this figure have a number of inflection points where accelerated ground deformations are occurring in response to engineering activity (blasting of new excavations in the vicinity). To reproduce a similar displacement profile during model calibration, the same stages of excavation construction must be incorporated in the simulated sequence, and temporal uncertainties must not be overlooked. The instrument was installed sometime after initial construction of the excavation, and so the data origin (zero displacement) does not represent the true onset of ground reaction (and it is nearly impossible to know how much rock mass strain has accumulated prior to instrument installation). Further, inconsistent data acquisition has resulted in one obvious period of accelerated ground movement, however it is difficult to discern the point in time where that acceleration event began. If multiple engineering activities occurred over that same period, it may be difficult to discern the physical drivers of measured ground reaction (however, numerical back analysis during the calibration process is likely to provide some insight).

Calibration to physical measurements is very straightforward as measured deformation and stress can be directly correlated to simulated deformation and stress. Figure 10 provides an example of model calibration to radar data monitoring slope deformations for the Santo Niño pit at Pinos Altos (from Kalenchuk et al. 2019). Figure $10 a$ shows a photo of the pit wall with a number of distinct zones defined by geotechnical domains and movement rates. Geotechnical domains delineate the spatial extent of rock mass units which have varying mechanical behaviour due to differences in rock mass strength and stiffness. For the Santo Niño crown pillar study, geotechnical domains are defined by lithological boundaries and structural features. The geotechnical domains are sub-domained based on movement rates; the numerical values illustrate measured deformation in millimetres over a May 2015 to June 2016 monitoring period.

Figure $10 b$ illustrates numerically predicted deformations over the same temporal period. The simulated deformation magnitudes can be compared directly to measured slope movements over the same life-of-mine period. The calibration process aims to numerically reproduce measured ground reactions, and this requires systematic adjustment of material properties (within reasonable ranges based on the available site characterization data) and boundary conditions (such as stress and ground water). The arrows indicate areas with good correlation and poorer correlation. Generally, there is a good match between measured and simulated deformations (low deformation areas are within 10s of millimetres and high deformation areas are within a few 100 s of 
Fig. 10. Example of calibration to measured deformations shows a comparison of pit slope radar data to numerically predicted deformations: (a) cumulative displacements (in $\mathrm{mm}$ ) for May 2015 to June 2016 vs. (b) cumulative displacements produced by numerical models for the same period (Kalenchuk et al. 2019).

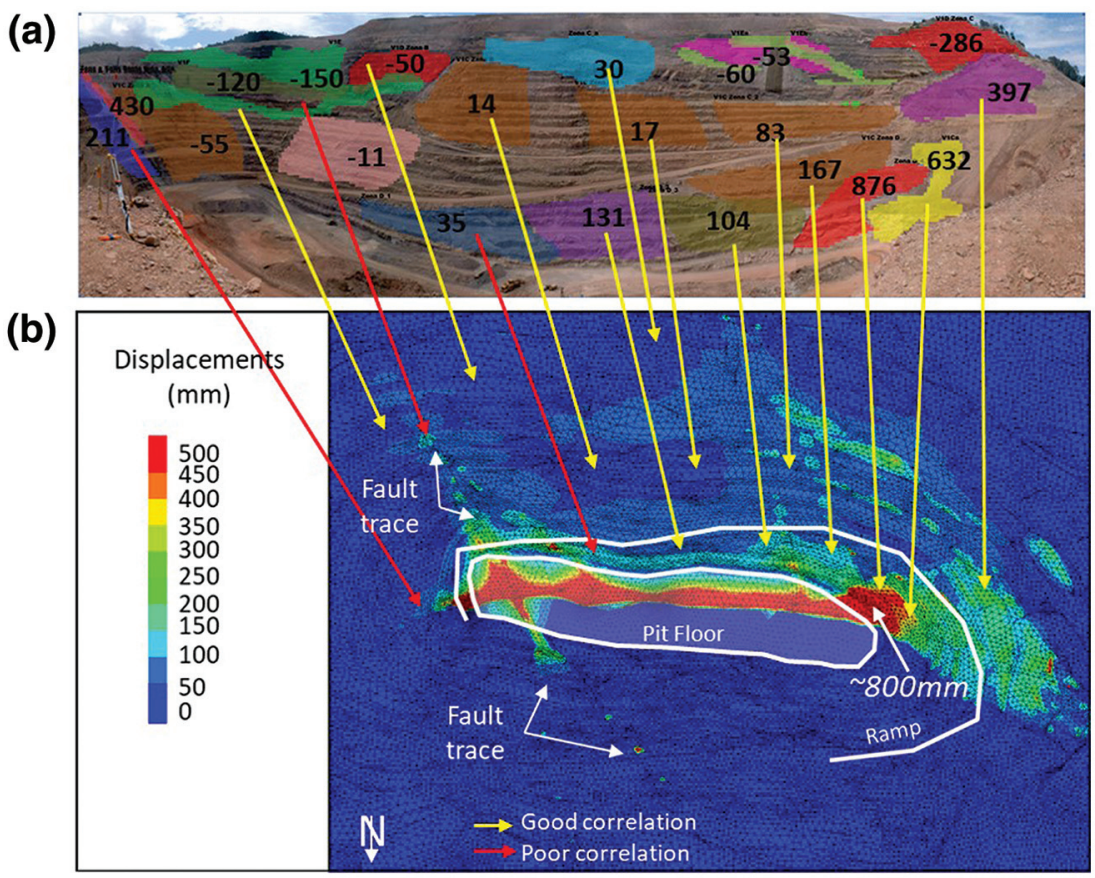

millimetres). Areas which appear to have poorer correlation have, for this study, been reviewed to understand the contributing factors. For example, at the far east end of the pit (left side of Fig. 10), localized erosional events are captured in the radar data and are not mechanically represented by numerical simulations.

To avoid common mistakes, two key points must be considered when calibrating to conventional instrumentation. First, it is important to ensure that simulated deformations and stress changes are compared to measured ground reaction over the same temporal period (e.g., model deformations should be normalized, or "zeroed", at the point in time when instruments were installed so that accumulated deformations can be compared directly to physical data). Second, when using measured ground reaction, the directional vector of measured movement or stress change must be compared to the same directional vector in numerical simulations. For example, considering the slope example shown in Fig. 10, pit radar systems measure deformations parallel to the radar line of site (slope parallel displacements are not intrinsically detected by the radar data, Hawley et al. 2009), and so numerical deformation magnitudes have been analysed on the same directional vectors.

\section{Calibrating to microseismic data}

Sophisticated seismic monitoring systems are routinely used to monitor ground reaction, particularly in mining and petroleum geomechanics. Seismic data are arguably one of the most valuable tools for model calibration at the global scale. The means to represent seismicity in numerical models varies depending on the type of seismicity being investigated: discrete event(s) associated with fault slip versus dispersed seismicity where event clusters are associated with failure of a rock mass volume. Microseismic data can provide the full four-dimensional extent of where and when a rock mass or structure is transitioning through the yielding process, and characterizes the energy released during fracturing and deformation. While some components of stress change and structural slip can be back-analysed from source mechanisms, seismic data does not provide any direct measure of stress or total accumulated strain, and so absolute definition of constitutive models (particularly post-peak parameterization) in the absence of adequate site characterization data can be difficult.

Like any form of ground reaction data, a logical first step to calibrating a model to seismic ground response is to conduct a detailed review of seismic data to develop interpretations of the spatial and temporal distributions of seismogenic behaviour. This is a key part of the ground behaviour model, and often involves seismic domaining. Only once the ground behaviour model has been developed and the practitioner has a comprehensive understanding of seismic ground response should the development and calibration of the numerical model be initiated.

Discontinuum numerical methods often utilize excess shear stress (Ryder 1988) and (or) formulation of seismic moment. These are applicable to fault or joint models and can also be applied to complex discrete fracture networks (DFNs). Calibrating the response of a known structure with known seismic mechanism at a discrete excavation stage can be fairly straightforward. For instance, the seismic moment of a shear slip event can be defined as a function of the rock mass shear modulus $(G)$, ride on a fault or fracture surface $(D)$, and the area of the slip surface $\left(A_{\text {slip }}\right)$, using eq.1(Aki and Richards 1980):

(1) $\quad M_{\mathrm{o}}=G A_{\text {slip }} D$

However, calibration and model interpretation for discrete slip events are complicated by assumptions related to whether all simulated slip occurs during one seismic event or if slip evolves over a period of multiple events. This form of calibration is also difficult when the structure in question is unknown or poorly defined (e.g., where large shear rupture events occur in a rock mass volume where no structures are known or delineated in the geological model).

The calibration of a discontiuum model to dispersed seismicity is generally not practical as there are significant limitations. A DFN is required and, due to typical limitations in geomechanical data, there is often significant uncertainty in the definition of joint distributions (persistence and spacing) and the parameterization 
Fig. 11. Correlation between $(a)$ an overlay of seismic data on a numerical model cross section showing pre- and post-peak rock mass regions to $(b)$ rock mass stress-strain path.

(a)

\section{Cross-section through numerical model with measured seismicity overlain}

(b)

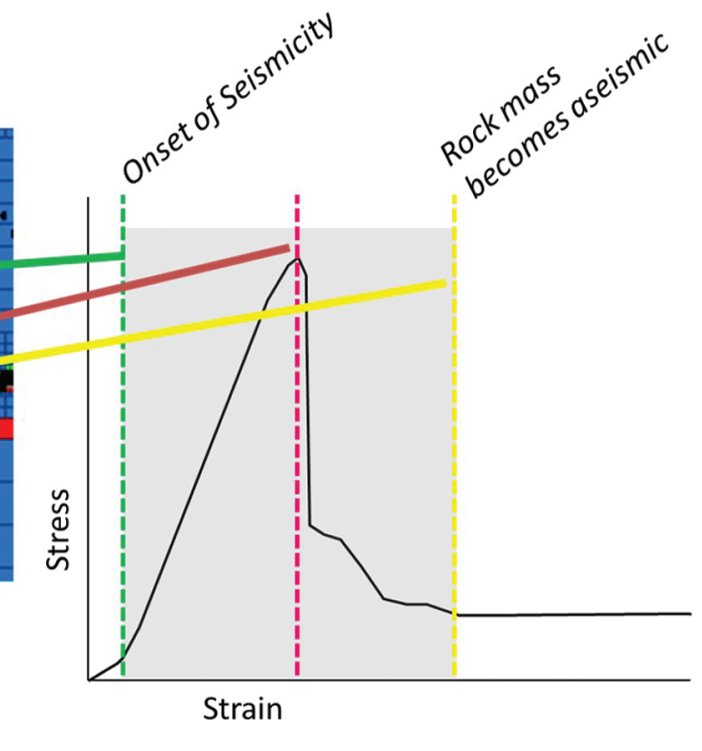

of contact properties (strength and stiffness). Discontinuum DFN models rely on the assumption that all events involve shear on existing fractures at known orientations, whereas FEMDEM simulations can capture events related to fracture initiation, growth, and interaction. Unfortunately, the discrete simulation of dispersed seismicity is generally hindered by computational efficiencies, particularly where hybrid methods are required.

Continuum models are practical for the numerical representation of dispersed seismicity (a term that generalizes seismogenic response of a rock mass volume transitioning through the failure process rather than fault-slip where failure occurs on a structure that is of significant size relative to the volume of interest). And so, continuum models provide an excellent means for spatial and temporal mapping of seismic susceptibility or making estimation of seismic intensity (both of which are crucial inputs for seismic risk assessments and hazard mapping). Seismic susceptibility mapping identifies rock mass volumes that are likely to be, or become, seismically active based on numerical output; seismic susceptibility is commonly correlated to yield, stress state, and (or) strain accumulation (or combinations of these numerical output which resolve parameters such as work or energy).

Continuum models can be qualitatively calibrated to seismic data by mapping direct numerical output (stress, strain, yield) against seismic data. For example, numerically predicted zones of rock mass yielding can be compared to seismically active regions of the rock mass. In this case practitioners must be careful to avoid the common misconception that "yielded" volumes in a numerical model are indicative of aseismic conditions. A numerical state of "yield" generally indicates that a volume is post peak, which should not be misconstrued as residual. The onset of seismicity in a rock mass occurs well before peak strength (in laboratory samples this correlates to the crack initiation threshold), and seismic events should continue to occur until residual strength is achieved (i.e., when the rock is completely failed). This is why seismic events should cluster near the yield front of a well calibrated model with events locating within both the elastic and plastic volumes, as schematically illustrated in Fig. 11.

Visually mapping seismogenic behaviour to numerical output is a qualitative and somewhat subjective approach to seismic modelling calibration. While this can provide broad indications of where (spatially and temporally) seismicity may be expected, it is very difficult to quantify forward looking seismic risk. Qualitative calibrations provide a "yes/no" prediction of seismic susceptibility; however, for informed decision making, it is necessary to quantify goodness of fit and then make a prediction for probability of occurrence.

When calibrating to seismic data, goodness of fit can be defined by how repeatable the numerical state (as defined by stress, strain, and yield) is when representing a seismogenic rock mass volume. This is particularly true for seismic onset (note that this stress/strain/yield state repeatability is domain specific and must be evaluated individually for each geotechnical domain in the rock mass volume being analysed). In the pre-peak elastic regions of a rock mass, the mechanical parameters (stiffness and strength) are relatively unchanged during loading (in contrast to the more significant post-peak changes to material strength and stiffness); therefore, it is reasonable to expect consistent stress and strain conditions for seismogenic ground reaction (spatially and temporally, for each individual geotechnical domain).

Numerically evaluating goodness of fit for the methods listed above is achieved by sampling the numerically simulated stress, strain, and yield state at every microseismic event location (ensuring that the appropriate temporal period or model stage is utilized for different time periods). With these data, goodness of fit can be statistically evaluated by various methods, these are described below. The process of quantifying goodness of fit must be conducted independently for each geotechnical domain in the volume of interest to iteratively narrow in on the appropriate combinations of stress state and material properties.

The proportion of seismic events which occurs in elastic regions of a rock mass depends on numerous factors including (but not limited to) stress-path and strain-path history, material properties and brittleness. Conceptually, for a given geotechnical domain, the proportion of seismic events located within elastic vs. plastic regions of a numerical model should be relatively consistent over the simulation period (i.e., all model stages). In this sense, a yes/no flag for yielded elements can be used to quantify goodness of fit for a qualitatively calibrated model. Of course, care should be taken for complex life-of-mine applications where 
Fig. 12. Numerically sampled stress conditions at seismic event locations in pre-peak regions of a numerical model. In this case data are sampled on monthly intervals (each line) over a 2 year monitoring period. Model goodness of fit can be quantified by statistical variability of the results and correlation to damage threshold approximated by $30 \%$ to $50 \%$ of material UCS.

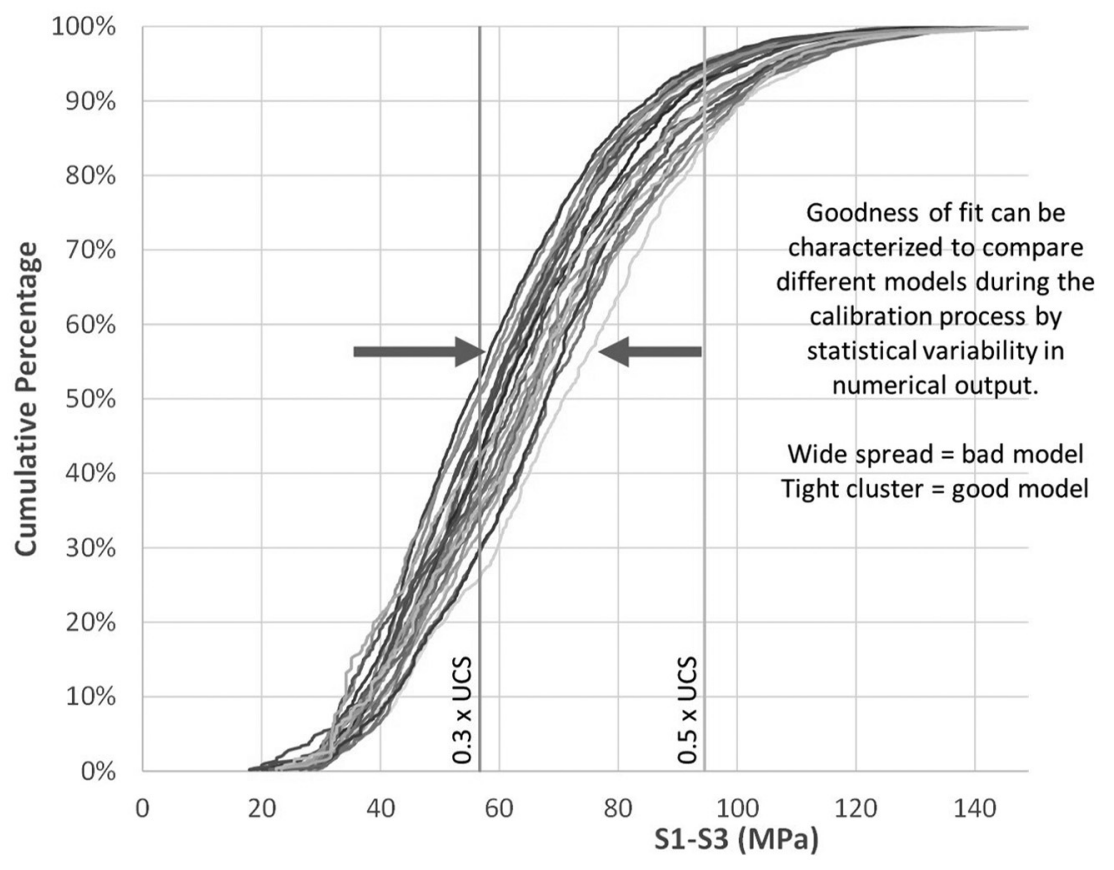

evolving extraction ratios can result in temporal creep of these proportionate statistics.

Seismicity is generated in a rock mass when new fractures are created or existing fractures propagate or shear. The onset of microseismicity in a rock mass begins when the stress state meets the damage threshold. The damage threshold envelope represents the onset of cohesion loss and friction mobilization in brittle rocks. Exceeding this stress limit is associated with the onset of progressive damage and induced seismicity. The damage threshold can be simplified as a linear function (Martin 1994):

$$
\sigma_{1 \mathrm{crit}}=A(\mathrm{UCS})+B \sigma_{3}
$$

where $\sigma_{1 \text { crit }}$ is the major principal stress at onset of progressive damage, UCS is the unconfined compressive strength, and $\sigma_{3}$ is the minor principal stress.

The $A$ parameter generally varies between 0.3 and 0.5 depending on the rock type and, in the absence of laboratory testing, $B$ is commonly estimated to be 1.0 (it can vary between roughly 0.5 and 2.5). $A$ and $B$ both vary depending on rock type (mineralogy, grain-scale heterogeneity, etc.). Using the damage threshold envelope as an approximation for the onset of microseismicity in elastic materials provides a suitable tool for qualitative model calibration, and an example is demonstrated in Fig. 12. This figure illustrates stress state data sampled in a numerical model at the locations of thousands of seismic events over a 2 year monitoring period; statistical distributions have been generated for monthly time periods.

Ideally the steep portion of the cumulative percent less than distribution illustrated in Fig. 12 will fall within the 0.3UCS to $0.5 U C S$ range (this fit can be calibrated through systematic variation of boundary conditions and material strengths). Since the loading conditions at seismic onset (for a specific domain) should remain constant, the goodness of fit is improved where variance in numerical results is minimized. In a perfect situation, with excellent data and a homogenous rock mass, the statistical distribution of seismic onset should be statistically identical through all regions and stages; of course, data are rarely excellent, and rock is never homogenous. A perfect match stage over stage is exceptionally difficult and some variability is expected due to spatial variance in rock mass conditions (within each explicit geotechnical domain), as well as changes in the global system stiffness related to changing extraction ratio.

Another direct model output that works well for seismic data calibration is shear strain. Numerically predicted shear strain can be sampled at seismic event locations at appropriate points in the simulated historical extraction. Figure 13 illustrates an example of the cumulative distribution of shear strain at seismic event locations sampled annually, and the premise described above for repeatable statistical distributions for specific geotechnical domains applies. Calibration to shear strain works well when there is no major change in extraction ratio. One consideration that practitioners must be aware of when using shear strain as a calibration criterion is that system stiffness will change with change in extraction ratio. The more excavations you have in a volume of rock, the softer the system becomes - thereby changing the rock mass strain response (this is evident by the flattening trend of strain data with time as shown in Fig. 13).

Further to analysing stress and strain independently, as described above, the mathematical correlation between stress and strain can be used to define statistical trends and probability of occurrence. Figure 14 demonstrates the correlation between stress and strain sampled at seismic event locations in the pre-peak regions of two geotechnical domains within the same numerical model. Domain A has a well-defined linear correlation and normal distribution of data density across that linear trend. Domain B has a weaker linear trend and demonstrates a more complex data density distribution function. This demonstrates that Domain A is well calibrated and further work to improve Domain B is required. The poor statistical fit in Domain B may be attributed to poorly calibrated parameterization and (or) boundary conditions, or that two sub-domains may be occurring within Domain B (hence the bimodal data density distribution). To explore the latter case the ground behaviour model should be re-visited. 
Fig. 13. Example of the statistical distribution of numerically predicted accumulated shear strain at seismic event locations.

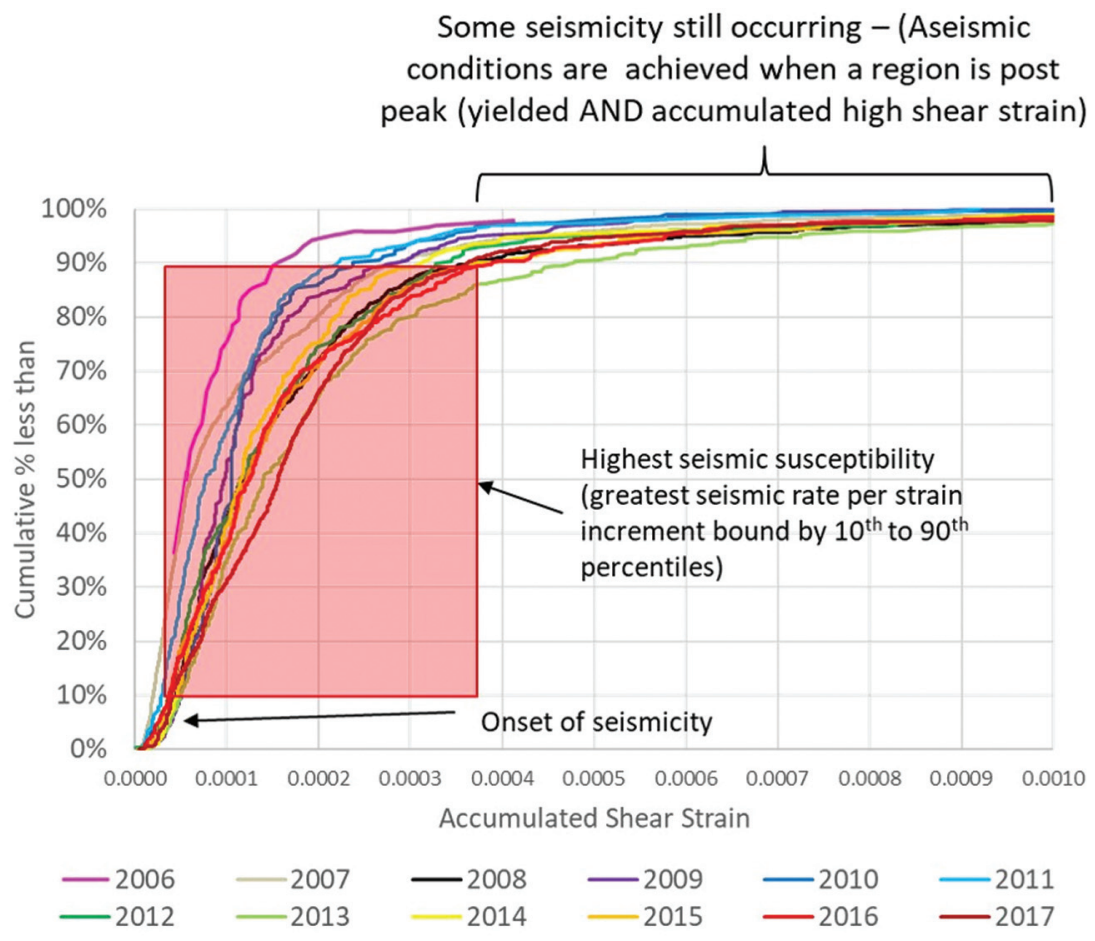

Fig. 14. Example of the mathematical correlation of stress and strain sampled in pre-peak regions of a numerical model for two material domains.
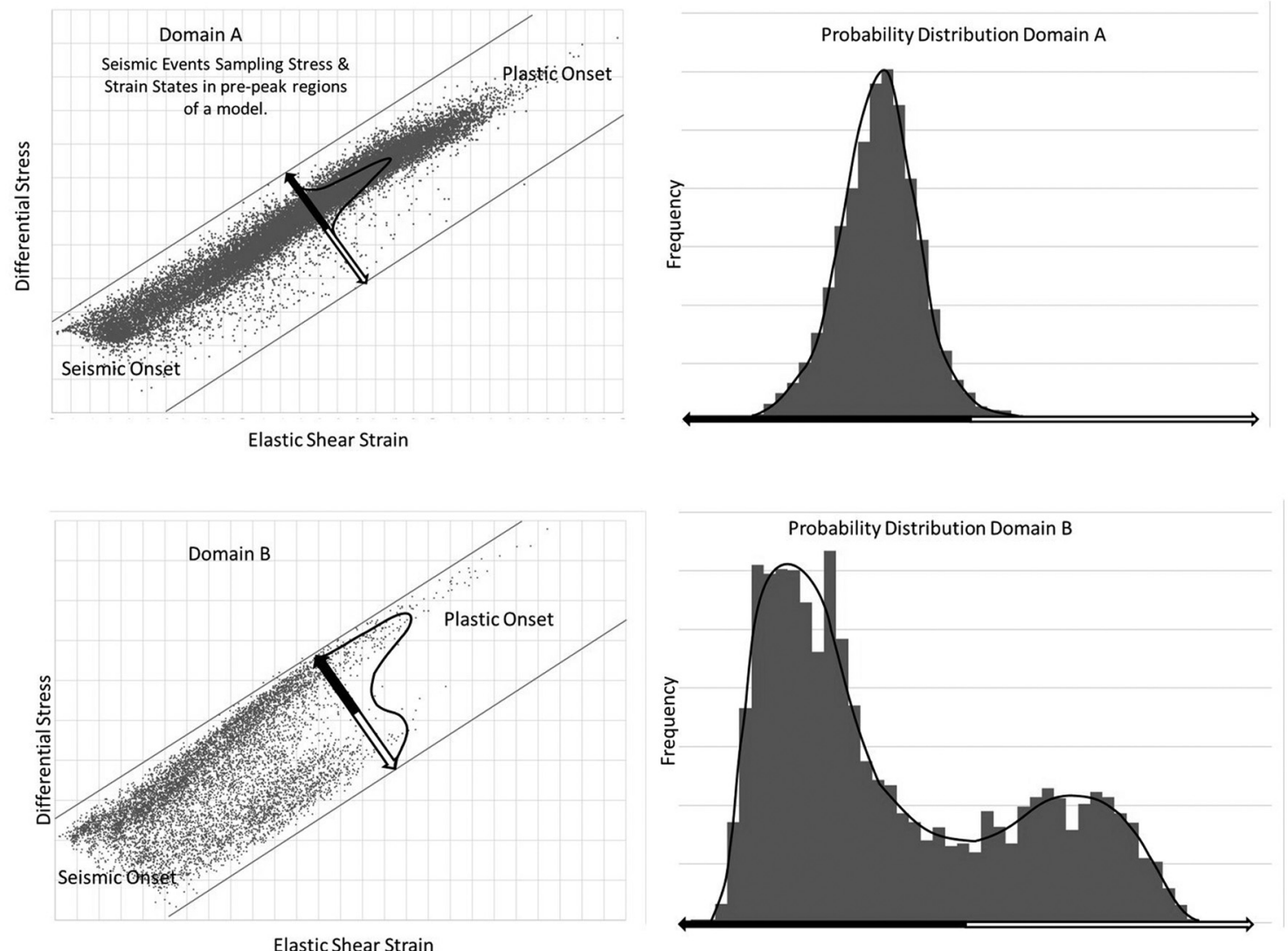
Once a model is calibrated to historical seismogenic behaviour, forward predictions for seismic hazard can be made because we are able to define the stress, strain and yield state conditions for seismogenic potential. More sophisticated model calibration can focus on analyses of seismic intensity. Various nomenclatures are used to quantitatively describe the intensity of seismicity in continuum models; energy release rate, local energy release density, modeled ground work, rate of energy release, etc. (e.g., Jager and Ryder 1999; Wiles 1998; Beck and Brady 2000). Despite the different terms applied to energy release potential, these state-ofpractice techniques for numerical simulation are fundamentally similar. Work, or energy, corresponds directly to the area under a stress-strain curve and the stiffness of a failing volume relative to the stiffness of the loading system dictates the intensity of energy release. By measuring load and strain in a numerical model, energy release can be defined within any given volume. To quantify numerical predictions of energy release, a numerical model must be discretized into test-blocks or sample volumes where the model response is monitored. Energy release for any given sample volume can be compared to measured seismicity for the represented volume. It is worth noting that calibrating to energy release should be conducted with caution; a significant challenge with test-block approaches is that the size and shape of a test-block can influence the interpretation of both measured microseismicity and numerical output (this is demonstrated by Beck and Brady 2002). When the measured ground reaction and the interpretation of simulated ground reaction are sensitive to test-block geometry, exceptionally time-consuming sensitivity testing is required. In the absence of sensitivity testing the analyses run are at risk of being fatally flawed. For most practical applications it is acceptable to utilize numerical models for seismic susceptibility evaluations; where in parallel to evaluating seismogenic potential, site specific seismic data records can be utilized to make predictions of seismic intensity based on well-established geophysical principals ( $B$-values, decay laws, etc.).

\section{Conclusions}

Numerical modelling in modern geomechanics and geotechnical engineering is evolving rapidly and making significant contributions to our field. However, there exist significant flaws in the day-to-day application of numerical methods by geomechanics practitioners, the most significant of which are overconfidence placed in numerical results and disregard (or lack of understanding) of the uncertainties in uncalibrated numerical output. Uncertainty in the parameterization of rock masses and definition of boundary conditions (model input) must be carried forward to numerical output, as design sensitivities related to parametric uncertainty can drastically impact project safety and economics. Failure to recognize design uncertainty can result in unforeseen fatal flaws.

Unfortunately, practitioners are routinely overlooking the fact that the degree of complexity incorporated in a numerical model must be justified by (i) the quality and quantity of geomechanical data available for material parameterization, (ii) the degree of confidence in assumed boundary conditions, and (iii) the rigor of calibration. To be successful at numerical modelling, practitioners must answer a few key questions before starting a modelling exercise:

1. What is the modelling exercise objective (mechanistic vs. susceptibility)?

2. What type of model is appropriate with consideration for ground reaction mechanisms and scale?

3. What constitutive model is appropriate (justification of constitutive model complexity must be based on the data available to characterize the rock mass stress-strain path)?
4. What boundary conditions are appropriate? How should the boundary conditions be initialized?

5. How much uncertainty exists in the numerical input? How does uncertainty impact the resulting engineering design?

6. What data exist for calibration to facilitate the reduction of uncertainty?

It has been established that the key to reducing uncertainty, improving result accuracy, and gaining confidence in numerical output is calibration. However, despite the wide application of numerical models to geomechanical engineering and the general consensus that models should be calibrated, there is little, or no, formal training on the topic of model calibration. This paper has described a framework to guide geomechanics professionals through model calibration, highlighting the opportunities and limitations of specific types of ground reaction data.

\section{Acknowledgements}

Thanks are extended to the Canadian Geotechnical Society and the Canadian Foundation for Geotechnique for providing the author with the opportunity to present the CGS 2019 Colloquium at St. John's 2019 (the 72nd Canadian Geotechnical Conference), and subsequently at numerous Canadian cities during the Cross Canada Colloquium lecture tour. The privilege to engage with geotechnical engineering practitioners and students from across the country has been very rewarding.

\section{References}

Aki, K., and Richards, P. 1980. Quantitative seismology: theory and methods. W.H Freeman and Co., San Francisco, Calif.

Beck, D., and Brady, B. 2000. A numerical method for engineering management of induced seismic Risk in hard rock mining. In Proceedings of the 5th International Symposium on Rockbursts and Seismics in Mines, Johannesburg.

Beck, D., and Brady, B. 2002. Evaluation and application of controlling parameters for seismic events in hard-rock mines. International Journal of Rock Mechanics and Mining Sciences, 39: 633-642. doi:10.1016/S1365-1609 (02)00061-8.

Crockford, A., Kalenchuk, K., and Bawden, W. 2015. Calibration of inelastic constitutive behaviour at a late stage mine and the problems associated with data limited calibration. In Proceedings of the 49th US Rock Mechanics Symposium, San Francisco, Calif., 29 June - 1 July 2015.

Crowder, J., Coulson, A., and Bawden, W. 2006. The field-scale rock mechanics laboratory: estimation of post-peak parameters and behaviour of fractured rock masses. In Proceedings of the 41st US Rock Mechanics Symposium, Golden, Colo., 17-21 June 2006.

Diederichs, M.S. 1999. Instability of hard rockmasses: The role of tensile damage and relaxation. Ph.D. thesis, University of Waterloo, Waterloo, Ontario.

Diederichs, M.S. 2003. Rock fracture and collapse under low confinement conditions. Rock Mechanics and Rock Engineering, 36: 339-381. doi:10.1007/s00603-003-0015-y.

Eberhardt, E., Lavoie, T., and Rahjoo, M. 2019. The importance of geometric dilation in response to brittle rock failure for support design in high stress environments. In Proceedings of the 14th International Congress on Rock Mechanics and Rock Engineering (ISRM 2019), Foz do Iguassu, Brazil, 13-18 September 2019.

Hawley, M., Marisett, S., Beal, G., and Stacey, P. 2009. Chapter 12: Performance assessment and monitoring. In Guidelines for open pit slope design. Edited by J. Read and P. Stacey. CSIRO Publishing, Collingwood, Australia. pp. 327-380.

Hoek, E., Carranza-Torres, C., and Corkum, B. 2002. Hoek-Brown failure criterion - 2002 Edition. In Proceedings of the 5th North American Rock Mechanics Symposium, Toronto, Ont., 7-10 July 2002. pp. 267-273.

Jager, A., and Ryder, J. 1999. A handbook on rock engineering practice for tabular hard rock mines. The Safety in Mines Research Advisory Committee (SIMRAC), Johannesburg, South Africa.

Kalenchuk, K., Crockford, A., Hume, C., Milner, N., and Watson, J. 2014. Application of numerical modelling to predict seismic probability and mitigate associated risks during the Craig Pillar extraction at Morrison Mine, KGHM International. In Proceedings of the 48th US Rock Mechanics/Geomechanics Symposium, Minneapolis, Minn., 1-4 June 2014.

Kalenchuk, K., Mercer, R., and Williams, E. 2017. Large-magnitude seismicity at the Westwood mine, Quebec, Canada. In Proceedings of the 8th 
International Conference on Deep and High Stress Mining, Perth, Australia, 28-30 March 2017. pp. 89-101.

Kalenchuk, K., Falmagne, V., Gelover, A., Montiel, I., and Luzania, J. 2019. Risk evaluation, design, implementation, instrumentation, and verification for Crown Pillar extraction at Pinos Altos Mine. Rock Mechanics and Rock Engineering, 52(12): 4997-5011. doi:10.1007/s00603-019-01801-z.

LeRiche, A., Kalenchuk, K., and Diederichs, M.S. 2017. Estimation of in situ stress from borehole breakout for improved understanding of excavation overbreak in brittle anisotropic rock. In Deep Mining 2017: Proceedings of the 8th International Conference on Deep and High Stress Mining, Perth, Western Australia, 28-30 March 2017. pp. 209-222.

Martin, C.D. 1994. The strength of massive Lac du Bonnet granite around underground openings. Ph.D. thesis, Department of Civil Engineering, University of Manitoba, Winnipeg, Man.

Palleske, C., Kalenchuk, K., Hume, C., and Bawden, W. 2017. Strategic use of geotechnical data for maximised value added. In Deep Mining 2017: Proceedings of the 8th International Conference on Deep and High Stress Mining, Perth, Western Australia, 28-30 March 2017. pp. 511-520. doi:10.36487| ACG_rep/1704_33_Palleske

Rahjoo, M., and Eberhardt, E. 2019. On the significance of recognizing the 3D directionality of fracturing under polyaxial stress states for understanding and modelling the 3D directional dilation of brittle rocks. In Proceedings of the 14th International Congress of Rock Mechanics and Rock Engineering (ISRM 2019), Foz do Iguassu, Brazil, 13-18 September 2019.

Rahjoo, M., Eberhardt, E., and Chandler, N.A. 2018. Development of a PSIRbased dilation model for brittle rock using parameters with physical meaning. In Proceedings of the 52nd US Rock Mechanics/Geomechanics Symposium, Seattle, Wash., 17-20 June 2018.

Ryder, J. 1988. Excess shear stress in the assessment of geologically hazardous situations. Journal of the South African Institute of Mining and Metallurgy, 88: 27-39. doi:10520/AJA0038223X_1867.

Sandy, M., Sharrock, G., Albrecht, J., and Vakili, A. 2010. Managing the transition from low stress to high stress conditions. In Proceedings of the 2nd Australasian Ground Control in Mining Conference, University of New South Wales, Sydney Australia, 23-24 November 2010.

Wiles, T. 1998. Correlation between local Energy Release Density and observed bursting conditions at Creighton Mine. Report for INCO Ltd. Mines Research, Sudbury, Ont.

Wiles, T. 2007. Evidence based model calibration for reliable predictions. In Deep Mining 2007: Proceedings of the Fourth International Seminar on Deep and High Stress Mining, Perth, Australia, 7-9 November 2007. pp. 3-20. 